\title{
Prescription in Patients with Chronic Kidney Disease-Perspective from Community and Family Physicians
}

\section{Desmond Y. H. Yap}

Department of Medicine, Queen Mary Hospital, The University of Hong Kong, 102 Pokfulam Road, Hong Kong

\begin{abstract}
Community and family physicians often encounter patients with chronic kidney disease (CKD). As compared to patients in the general population, CKD patients have altered drug metabolism and increased susceptibility to drug-induced nephrotoxicity. Factors which affect drug metabolism in CKD patients include impaired drug absorption due to significant uremia and use of concomitant medications, aberrant volume of distribution of drugs, reduced drug binding to albumin and decreased renal elimination of therapeutic compounds and its metabolites. Against these backgrounds, the avoidance of potentially nephrotoxic agents, appropriate dosage modification and minimization of drug interactions are essential in preventing adverse drug reactions in CKD patients. Avoidance of potentially nephrotoxic drugs can be achieved via careful review of the clinical indications of nephrotoxic drugs and consideration of non-nephrotoxic alternatives. Dosage modification should be based on the estimated glomerular filtration rate, which can be measured bydifferent established formula in daily clinical practice. The use of these formulas, however, should take into consideration the accuracy of tests, preference of clinicians and patients, severity of renal impairment and clinical context. Minimization of potential drug-drug interaction can help prevent many life-threatening complications, especially in CKD patients who receive cytotoxic or immunosuppressive therapies. Clinicians should also be alert to the teratogenicity of some common drugs used in CKD patients among female subjects of childbearing age. These measures and practices, when properly adhered and exercised, can ensure prescription safety in CKD patients.
\end{abstract}

\section{Introduction}

Chronic kidney disease (CKD) is a growing and important clinical entity, and is often encountered by community and family physicians during screening and management of other concomitant medical problems [1-3]. For instance, common chronic medical illnesses such as diabetes mellitus and hypertension are leading causes of CKD [3]. Also, the presence of renal impairment is an independent risk factor for important clinical outcomes such as cardiovascular disease [2] The kidneys assume crucial homeostatic functions which include the handling of fluid and electrolytes, secretion of hormones like erythropoietin and vitamin $\mathrm{D}$, regulation of blood pressure, excretion of uremic wastes and elimination of medicinal compounds. Patients with chronic kidney diseases often have altered pharmacokinetics and pharmacodynamics. More importantly, CKD patients exhibited heightened susceptibility to renal toxicities of nephrotoxic drugs. Furthermore, some common medications used in CKD patients are teratogenic and should be avoided or discontinued should pregnancy be contemplated. Without careful consideration in prescription and appropriate dosage modification, disastrous clinical outcomes can ensue. The following review elaborated on the changes in drug metabolism and pitfalls of prescription in CKD patients.

\section{Changes in pharmacokinetics and pharmacodynamics in patients with chronic kidney disease}

Impaired absorption of drugs is observed in CKD patients. The frequent use of phosphate-binders and proton pump inhibitors in CKD patients caninfluence absorption of other acidic medicinal compounds. Furthermore, patients with severe uremia exhibit nausea and repeated vomiting, which can substantially decrease the absorption of other oral medications. The significant decrease of serum albumin in patients with nephrotic syndrome can influence the distribution of highly protein-bound drugs and also the absorption of drugs due to gut edema. These drugs include warfarin and furosemide. As a result, the clotting profile has to be closely monitoring in nephrotic patients who receive warfarin treatment [4]. Also, high dose intravenous furosemide might be required to achieve the desired diuretic effects in patients with significant proteinuria [5]. Many drugs undergo oxidation/reduction and hydrolysis in the kidney before they are eliminated and these mechanisms might be impaired in patients with renal failure. More important, the excretion of drugs and its metabolites are diminished in patients with decreased glomerular filtration rate (GFR). The elimination of drugs constitutes a significant problem in dialysis patients. In hemodialysis patients, the clearance of drugs is dependent on the pore size of dialyzer as well as blood and dialysate flow rates during hemodialysis6. As for peritoneal dialysis, drug elimination is generally poor although drugs with small molecular size and high volume of distribution might assume slight advantage in clearance7. Protein loss in peritoneal dialysis fluid might also facilitate the elimination of highly protein-bound substances [7].

\section{Dosage adjustment in patients with chronic kidney disease}

In general, the modification of drug dosages should be based on GFR measurement (Table 1). In daily clinical practice, serum creatinine $(\mathrm{Cr})$ level remains a widely accepted and convenient indicator of renal function. However, the measurement of serum $\mathrm{Cr}$ can be problematic

*Corresponding Author: Dr. Desmond Y. H. Yap, NCB 301, Department of Medicine, Queen Mary Hospital, The University of Hong Kong, 102 Pokfulam Road, Hong Kong, Tel: (852)-22554384; E-mail: desmondy@hku.hk

Citation: Yap DYP (2016) Prescription in Patients with Chronic Kidney DiseasePerspective from Community and Family Physicians. Int J Community Fam Med 1: 105. doi: http://dx.doi.org/10.15344/ijcfm/2016/105

Copyright: (c) 2016 Yap.This is an open-access article distributed under the terms of the Creative Commons Attribution License, which permits unrestricted use, distribution, and reproduction in any medium, provided the original author and source are credited. 
Citation: Yap DYP (2016) Prescription in Patients with Chronic Kidney Disease-Perspective from Community and Family Physicians. Int J Community Fam Med 1: 105. doi: http://dx.doi.org/10.15344/ijcfm/2016/105

Page 2 of 5

\begin{tabular}{|c|c|c|}
\hline Methods & Equation & Remarks \\
\hline Serum creatinine $(\mathrm{Cr})$ & - & $\begin{array}{l}\text { - Pitfalls in patients with low muscle mass and } \\
\text { significant peripheral edema } \\
\text { Prone to drug disturbances (interference with } \\
\text { tubular excretion of Cr \& Cr assays) }\end{array}$ \\
\hline 24-hr urine collection & (24-hr urine $\mathrm{Cr} \div 24$-hr serum $\mathrm{Cr}$ ) x 0.7 & $\begin{array}{l}\text { - } \quad \text { Prone to error of collection } \\
\text { - } \quad \text { Cumber and not welcomed by patients }\end{array}$ \\
\hline Plasma Cystatin C & - & $\begin{array}{l}\text { - More sensitive than serum } \mathrm{Cr} \text { to detect early renal } \\
\text { dysfunction } \\
\text { - } \quad \text { Expensive and not widely available }\end{array}$ \\
\hline CG equation & $\begin{array}{l}\mathrm{CrCl}(\mathrm{mL} / \mathrm{min})=[(140-\text { Age }) \text { x lean } \mathrm{BW}(\mathrm{kg})] \div[\text { Serum } \mathrm{Cr} \\
(\mathrm{mg} / \mathrm{dL}) \text { x } 72] \\
\text { x } 0.85 \text { (if female) }\end{array}$ & $\begin{array}{l}\text { - } \\
\text { - } \quad \text { Accurate in stable renal function } \\
\text { - } \\
\text { and renal function }\end{array}$ \\
\hline MDRD equation & $\begin{array}{l}\mathrm{GFR}(\mathrm{mL} / \mathrm{min} / 1.73 \mathrm{~m} 2)=175 \mathrm{x}(\mathrm{SCr})^{-1.154} \mathrm{x}(\text { Age })^{-0.203} \times(0.742 \text { if } \\
\text { female }) \times(1.212 \text { if African American })\end{array}$ & $\begin{array}{l}\text { - } \quad \text { Accurate in moderate renal impairment } \\
\text { - } \quad \text { Can be imprecise in extremes of renal function }\end{array}$ \\
\hline CKD-EPI equation & $\begin{array}{l}\mathrm{GFR}=141 \times \min (\mathrm{SCr} / \mathrm{a} 1) \times \max (\mathrm{SCr} / \mathrm{K}, 1)^{-1.209} \times 0.993^{(\mathrm{Age})} \mathrm{x} \\
1.108 \text { (if female) } \times 1.159 \text { (if black) } \\
\mathrm{K}=0.7 \text { if female } \& 0.9 \text { if male } \\
\alpha=-0.392 \text { if female } \&-0.411 \text { if male } \\
\mathrm{Min}-\text { The minimum of } \mathrm{SCr} / \mathrm{K} \text { or } 1 \\
\mathrm{Max}-\text { The maximum of } \mathrm{SCr} / \mathrm{K} \text { or } 1 \\
\mathrm{SCr}(\mathrm{mg} / \mathrm{dL})\end{array}$ & $\begin{array}{l}\text { - Less bias than MDRD equation especially in patients } \\
\text { with higher GFR } \\
\text { - } \quad \text { Not widely adopted in many laboratories }\end{array}$ \\
\hline
\end{tabular}

Table 1. Available methods to estimate glomerular filtration rate in CKD patients.

CG equation: Cockcroft-Gault equation; MDRD equation: Modification of Diet in Renal Disease Study Equation; CKD-EPI equation: Chronic Kidney Disease Epidemiology Collaboration equation

in CKD subject who are often elderly with shrunken muscle mass or significant peripheral edema. Another major drawback in applying serum $\mathrm{Cr}$ to gaugekidneyfunction is related to itspredisposition to drug interaction. For instance, cimetidine and probenecid can inhibit tubular secretion of $\mathrm{Cr}$ whereas ascorbic acid and cephalosporins can interfere with $\mathrm{Cr}$ assays. The Cockcroft-Gault Equation represented another common and convenient way to estimate GFR. This formula, however, shows better accuracy in patients with stable renal function and might become less precise when there is rapidly varying clinical conditions and kidney function. The Modification of Diet in Renal Disease Study (MDRD) equation is another useful equation for the estimation of GFR and has been validated in Chinese patients8,9. The MDRD is most accurate in subjects with moderate renal impairmentyet can be imprecise at the extremes of kidney function. Other methods of eGFR measurement include Chronic Kidney Disease-Epidemiology Collaboration (CKD-EPI) equations, which based on the same four variables in the MDRD equation, was reported to show better performance and with less bias especially in patients with higher GFR10. However, this equation is still not widely adopted in many laboratories. Drugs which rely on substantial renal clearance would need dosage adjustment in CKD. Renal adjustment of dosage can be achieved by decrease in individual doses or the frequency of administration, depending on the characteristics of the drug. Dosage optimization in CKD patients can sometimes be facilitated by therapeutic monitoring of blood levels of drugs (e.g. vancomycin and aminoglycoside). Careful review of the clinical indications and consideration of alternatives can also help avoid the use of nephrotoxic drugs in CKD patients.

\section{Common pitfalls of prescription in patients with chronic kidney diseases}

\section{Drugs used in common infections}

Bacterial infection is common medical problem encountered in the community and family care setting. Beta-lactam antibiotics such as penicillin, amoxicillin (including augmentin), cephalosporin and quinolones usually require dosage reduction in CKD patients $[11,12]$. Nitrofurantoin and cotrimoxazole which are commonly used in patients with urinary tract infection can lead to nephrotoxicity should generally be avoided(contraindicated when eGFR $<60 \mathrm{ml} /$ $\mathrm{min} / 1.73 \mathrm{~m}^{2}$ and $<15 \mathrm{ml} / \mathrm{min} / 1.73 \mathrm{~m}^{2}$ for nitrofurantoin and cotrimoxazole respectively). Other nephrotoxic antibiotics include vancomycin and aminoglycosides and therapeutic monitoring of their blood levels needs to be performed if these agents are to be used. Herpes zoster infection is also a common clinical problem in the community. The dose of acyclovir should be properly adjusted according to eGFRand the side effects (confusion, crystallization of drugs in renal tubules, etc.)are generally more common when eGFR is $<60 \mathrm{ml} / \mathrm{min} / 1.73 \mathrm{~m}^{2}$ and hence should be carefully monitored.The use of oseltamivir for influenza in renal failure patients is associated with increased gastrointestinal side effects and dose reduction would be needed(eGFR 31-60 ml/min/1.73 $\mathrm{m}^{2}: 30 \mathrm{mg}$ bd for 5 days; eGFR11$30 \mathrm{ml} / \mathrm{min} / 1.73 \mathrm{~m}^{2}$ : $30 \mathrm{mg}$ daily for 5 days; avoid if eGFR $<10 \mathrm{ml} /$ $\left.\mathrm{min} / 1.73 \mathrm{~m}^{2}\right)$.Conventional anti-fungal agent such as amphotericin $B$ can accentuate renal deterioration, especially in patients with underlying CKD, and renal function and electrolytes should be closely monitored should these patients be treated with amphotericin. A liposomal form of amphotericin B might be associated with lower toxicity at the organ level and hence can be considered as a viable option if amphotericin needs to be used in CKD patients. Azole groups or newer anti-fungal agents such ecchinocandinsshould also be considered as alternatives in CKD patients. 
Citation: Yap DYP (2016) Prescription in Patients with Chronic Kidney Disease-Perspective from Community and Family Physicians. Int J Community Fam Med 1: 105. doi: http://dx.doi.org/10.15344/ijcfm/2016/105

Page 3 of 5

\begin{tabular}{|c|c|c|}
\hline Drugs & Potential problems in renal failure patients & Remarks \\
\hline \multicolumn{3}{|l|}{ Antimicrobials } \\
\hline Penicillin; cephalosporins; quinolones & $\begin{array}{ll}\text { - } & \text { Confusion, seizure } \\
\text { - } & \text { Acute interstitial nephritis }\end{array}$ & - $\quad$ Dosage reduction required \\
\hline Vancomycin aminoglycosides & - Direct nephrotoxicity & $\begin{array}{l}\text { Therapeutic monitoring might facilitate dosage } \\
\text { optimization }\end{array}$ \\
\hline Macrolides & $\begin{array}{ll}\text { - } & \text { Prolongation of } \mathrm{QT}_{c} \\
\text { - } & \text { EnhanceCNI toxicity }\end{array}$ & $\begin{array}{ll}\text { - } & \text { Monitor ECG changes } \\
& \text { Monitor CNI drug levels }\end{array}$ \\
\hline Rifampicin & $\begin{array}{ll}\text { - } & \text { Acute interstitial nephritis } \\
\text { - } & \text { Reduce CNI efficacy } \\
\end{array}$ & $\begin{array}{l}\text { Pre-emptive increase in CNI dosage and monitor drug } \\
\text { levels to avoid renal graft rejection }\end{array}$ \\
\hline Acyclovir & - Confusion, crystallization in renal tubules & Dosage reduction required \\
\hline Adefovir; tenofovir & - $\quad$ Renal deterioration; tubular defects & - Dosage reduction required \\
\hline Ganciclovir & - $\quad$ Severe marrow suppression & - Dosage reduction required \\
\hline Oseltamivir & - Gastrointestinal upset & - Dosage reduction required \\
\hline Amphotericin B & $\begin{array}{l}\text { Direct nephrotoxicityhypomagnesium, } \\
\text { hypokalemia }\end{array}$ & - Dosage reduction and monitoring of electrolytes \\
\hline \multicolumn{3}{|l|}{ Drugs for cardiovascular diseases } \\
\hline Digoxin & $\begin{array}{l}\text { - Digoxin overdose (nausea, vomiting, yellow } \\
\text { vision, arrhythmia) }\end{array}$ & $\begin{array}{l}\text { - } \quad \text { Dosage reduction required } \\
\text { - Caution in patients with hypo/hyperkalemia }\end{array}$ \\
\hline ACEI/ARB/Spironolactone & - $\quad$ Renal deterioration, hyperkalemia & Cautious in renal artery stenosis \\
\hline \multicolumn{3}{|c|}{ Chemotherapy \& Immunosuppressive drugs } \\
\hline Cyclophosphamide & - $\quad$ Severe marrow suppression & - $\quad$ Dosage reduction required \\
\hline Methotrexate & - $\quad$ Severe marrow suppression & - Dosage reduction required \\
\hline Calcineurin inhibitors (CNI) & - Acute and chronic nephrotoxicity & Therapeutic drug monitoring useful \\
\hline \multicolumn{3}{|l|}{ Drugs for metabolic diseases } \\
\hline Sulphonylurea & - $\quad$ Risk of hypoglycemia & $\begin{array}{ll}\text { - } & \begin{array}{l}\text { Dosage reduction required in mild renal } \\
\text { impairment } \\
\text { - Avoid in significant renal dysfunction }\end{array} \\
\end{array}$ \\
\hline Biguanides (metformin) & - $\quad$ Severe lactic acidosis & - $\quad$ Avoid in renal failure patients \\
\hline DDP-4 inhibitors (except linagliptin) & - $\quad$ Risk of hypoglycemia & - Dosage reduction required \\
\hline (PPAR- $\gamma$ ) agonists & $\begin{array}{l}\text { - Precipitate fluid overload and congestive } \\
\text { heart failure }\end{array}$ & $\begin{array}{l}\text { - Avoid in CKD patients who are prone to fluid } \\
\text { overload and have underlying cardiac failure }\end{array}$ \\
\hline Allopurinol & $\begin{array}{ll}\text { - } & \text { Marrow suppression } \\
\text { - } & \text { Acute interstitial nephritis }\end{array}$ & $\begin{array}{l}\text { - } \quad \text { Dosage reduction required } \\
\text { - } \quad \text { Avoid concomitant azathioprine }\end{array}$ \\
\hline \multicolumn{3}{|l|}{ Drugs for gastrointestinal disease } \\
\hline $\mathrm{H}_{2}$ antagonists & Confusion & Dosage reduction required \\
\hline Proton pump inhibitors & $\begin{array}{l}\text { - } \quad \text { Acute interstitial nephritis } \\
\text { - Impaired absorption of other acidic drugs }\end{array}$ & $\begin{array}{ll}\text { - } & \text { Monitoring of renal function } \\
\text { Discontinuation if interstitial nephritis }\end{array}$ \\
\hline \multicolumn{3}{|l|}{ Analgesics } \\
\hline NSAIDS \& COX2 inhibitors & $\begin{array}{l}\text { - Direct nephrotoxicity, acute interstitial } \\
\text { nephritis }\end{array}$ & - $\quad$ Avoid in renal failure patients \\
\hline Opioid analgesics & $\begin{array}{l}\text { - Confusion \& respiratory depression in } \\
\text { patients with advanced CKD }\end{array}$ & - $\quad$ Avoid in advanced CKD patients \\
\hline
\end{tabular}

Table 2. Common drugs which can be problematic in patients with chronic kidney disease (CKD)

COX-2 inhibitors = Cyclo-oxygenase inhibitors; DDP- 4 inhibitors $=$ Dipeptidyl peptidase- 4 inhibitors; NSAID = Non-steroidal anti-inflammatory drugs; $($ PPAR- $\gamma)$ agonists $=$ Peroxisome proliferator-activated receptor gamma agonists 
Citation: Yap DYP (2016) Prescription in Patients with Chronic Kidney Disease-Perspective from Community and Family Physicians. Int J Community Fam Med 1: 105. doi: http://dx.doi.org/10.15344/ijcfm/2016/105

Page 4 of 5

Drugs used in cardiovascular diseases

Renin-angiotensin-aldosterone blocking agents are commonly used in patients with CKD for renal protection, reduction of proteinuria and control of blood pressure. The use of angiotensin converting enzyme inhibitor (ACEI) or angiotensin receptor blocker (ARB) can precipitate renal deterioration in patients with pre-existing renal artery stenosis or severe kidney dysfunction(e.g. Stage 4-5 CKD). Clinicians should look for renal bruits before embarking on ACEI/ $\mathrm{ARB}$ and closely monitor renal function tests after their initiation. A rise of serum $\mathrm{Cr}>15 \%$ above baseline would generally require discontinuation of these agents. Furthermore, hyperkalemia is also a common problem in the use of ACEI/ARB in CKD patients. Patients should be advised to consume low potassium diets to prevent these unwanted complications. Other anti-hypertensives such as alphablockers, beta-blockers, calcium channel blockers, hydralazine and methyldopa are generally safe in CKD patients. Digoxin is a commonly used rate-controlling agent in patients with atrial fibrillation. The use of digoxin in CKD patients can be complicated, especially in those with hypo/hyperkalemia and hence proper dosage reduction should be exercised.

\section{Drugs used in cardiovascular diseases}

Diabetes mellitus is one of the most common medical problems encountered in family physicians. Many oral hypoglycemic agents such as sulphonylurea and dipeptidyl peptidase-4 (DPP4) inhibitors (except linagliptin) require appropriate dosage modification [13,14] The use of metformin can result in severe lactic acidosis and should be avoided in patients with moderate to severe kidney dysfunction (The author would generally avoid metformin in patients with serum $\mathrm{Cr}>150 \mu \mathrm{mol} / \mathrm{L})$. Peroxisome proliferator-activated receptor gamma (PPAR- $\gamma$ ) agonists should not be used in CKD patients as they are associated with increased risk of cardiovascular events and fluid overload15. In general, switching to insulin therapy should be considered in patients with moderate to severe reduction in GFR(e.g. eGFR $<30 \mathrm{ml} / \mathrm{min} / 1.73 \mathrm{~m}^{2}$ ). Gout and hyperuricemia is commonly associated with CKD. The dose of allopurinol should be adjusted according to renal function (eGFR $10-20 \mathrm{ml} / \mathrm{min} / 1.73 \mathrm{~m}^{2}: 100-200 \mathrm{mg} /$ day; eGFR $<10 \mathrm{ml} / \mathrm{min} / 1.73 \mathrm{~m}^{2}: 100 \mathrm{mg}$ daily)and colchicine should be used with caution in CKD patients in view of their potential to cause myopathy.

\section{Drugs used in malignancy conditions and autoimmune diseases}

Many cytotoxic agents and immunosuppressants require significant dosage modification in CKD patients. Examples include cyclophosphamide, methotrexate and mycophenolic acid (MPA) [16-18]. The failure to adjust dosage of these agents according to renal function might result in severe myelosuppression, and hence life-threatening infective complications. There are also some lethal drug-drug interaction for treatments commonly used in autoimmune kidney diseases such as allopurinol and azathioprine (AZA) [19]. Very often substitution with other immunosuppressive agents might be needed before initiation of allopurinol and patients should be referred to the relevant specialists. Caution should be also exercised during prescription of other medications for CKD patients who are receiving calcineurin inhibitors (CNI). Rifampicin will induce CYP450 to enhance CNI metabolism and lead to reduced efficacy of CNI [20] Conversely, the use of macrolide antibiotics or azoles for fungal infection will inhibit CYP450 and hence increase the nephrotoxic and immunosuppressive effects of CNI [20].

\section{Drugs used for analgesia}

Non-steroidal anti-inflammatory drugs (NSAIDS) are wellrecognized nephrotoxic analgesics. NSAIDs can lead to acute renal failure, glomerulonephritis (e.g. membranous nephropathy), acute or chronic interstitial nephritis and papillary necrosis [21]. CKD patients are at increased risk of the NSAID-related nephrotoxic side effects and the risk correlated with the severity of CKD. Cyclo-oxygensase 2 (COX2) inhibitors cause less gastrointestinal problems, but their nephrotoxic effects appear to be similar to NSAIDs [22]. Other painkillers such as paracetamol, weak or strong opioids are generally safe in CKD patient, although previous studies have reported that opioids and its metabolites can accumulate in patients with advanced CKD [23].

\section{Teratogenicity of drugs commonly used in CKD patients}

Many drugs commonly used in CKD patients have teratogenic potential and have to be discontinued when pregnancy is contemplated. One good example is ACEI/ARB which can cause renal agenesis in the fetus [24]. Clinicians should take the initiative to enquire for pregnancy plans in female CKD patients in the reproductive age. ACEI/ARB should be discontinued and the blood pressure/proteinuria be closely monitored in patients who wish to get pregnant. MPA, a commonly used maintenance therapy in autoimmune glomerular diseases, can cause teratogenicity and might be replaced by AZA or CNI if pregnancy is considered [25]. The decision of changing immunosuppressive treatments should also take into consideration the past history of flare and current disease activity.

\section{Conclusion}

CKD patients have altered drug metabolism and increased susceptibility to nephrotoxic medications. Avoidance of nephrotoxic drugs and potential drug interactions, appropriate adjustment of dosage and vigilant monitoring of renal functioncan help minimize unwanted side effects of these agents in CKD patients.

\section{Competing Interests}

The authors declare that they have no competing interests.

\section{References}

1. Coresh J, Selvin E, Stevens LA, Manzi J, Kusek JW, et al. (2007) Prevalence of chronic kidney disease in the United States. JAMA 298: 2038-2047.

2. Sarnak MJ, Levey AS, Schoolwerth AC, Coresh J, Culleton B, et al. (2003) Kidney disease as a risk factor for development of cardiovascular disease: a statement from the American Heart Association Councils on Kidney in Cardiovascular Disease, High Blood Pressure Research, Clinical Cardiology, and Epidemiology and Prevention. Hypertension 42: 1050-1065.

3. Gregg EW, Cheng YJ, Cadwell BL, Imperatore G, Williams DE, et al. (2005) Secular trends in cardiovascular disease risk factors according to body mass index in US adults. JAMA 293: 18681874.

4. Ganeval D, Fischer AM, Barre J, Pertuiset N, Dautzenberg MD, et al. (1986) Pharmacokinetics of warfarin in the nephrotic syndrome and effect on vitamin K-dependent clotting factors. Clin Nephrol 25: $75-80$. 
Citation: Yap DYP (2016) Prescription in Patients with Chronic Kidney Disease-Perspective from Community and Family Physicians. Int J Community Fam Med 1: 105. doi: http://dx.doi.org/10.15344/ijcfm/2016/105

Page 5 of 5

5. Kodner C (2009) Nephrotic syndrome in adults: diagnosis and management Am Fam Physician 80: 1129-1134

6. Lee CS, Marbury TC (1984) Drug therapy in patients undergoing haemodialysis. Clinical pharmacokinetic considerations. Clin Pharmacokinet 9: 42-66.

7. Hirata S, Kadowaki D (2012) Appropriate drug dosing in patients receiving peritoneal dialysis. Contrib Nephrol 177: 30-37.

8. Levey AS, Bosch JP, Lewis JB, Greene T, Rogers N, Roth D (1999) A more accurate method to estimate glomerular filtration rate from serum creatinine: a new prediction equation. Modification of Diet in Renal Disease Study Group. Ann Intern Med 130:461-70.

9. Ma YC, Zuo L, Chen JH, Luo Q, Yu XQ, et al. (2006) Modified glomerular filtration rate estimating equation for Chinese patients with chronic kidney disease. J Am Soc Nephrol 17: 2937-2944.

10. Levey AS, Stevens LA, Schmid CH, Zhang YL, Castro AF 3rd, et al. (2009) A new equation to estimate glomerular filtration rate. Ann Intern Med 150: 604-612.

11. Munar MY, Singh H (2007) Drug dosing adjustments in patients with chronic kidney disease. Am Fam Physician 75: 1487-1496.

12. Marks M, Hirshfeld S (1968) Neurotoxicity of penicillin. N Engl J Med 279: 1002-1003.

13. Snyder RW, Berns JS (2004) Use of insulin and oral hypoglycemic medications in patients with diabetes mellitus and advanced kidney disease. Semin Dial 17: 365-370.

14. Mikhail N (2012) Use of dipeptidyl peptidase-4 inhibitors for the treatment of patients with type 2 diabetes mellitus and chronic kidney disease. Postgrad Med 124: 138-144.

15. Blind E, Dunder K, de Graeff PA, Abadie E (2011) Rosiglitazone: a European regulatory perspective. Diabetologia 54: 213-218.

16. Haubitz M, Bohnenstengel F, Brunkhorst R, Schwab M, Hofmann U, et al (2002) Cyclophosphamide pharmacokinetics and dose requirements in patients with renal insufficiency. Kidney Int 61: 1495-1501.

17. Murashima M, Adamski J, Milone MC, Shaw L, Tsai DE, et al. (2009) Methotrexate clearance by high-flux hemodialysis and peritoneal dialysis: a case report. Am J Kidney Dis 53: 871-874.

18. Meier-Kriesche HU, Shaw LM, Korecka M, Kaplan B (2000) Pharmacokinetics of mycophenolic acid in renal insufficiency. Ther Drug Monit 22: 27-30.

19. Gearry RB, Day AS, Barclay ML, Leong RW, Sparrow MP (2010) Azathioprine and allopurinol: A two-edged interaction. J Gastroentero Hepatol 25: 653-655.

20. [No authors listed] (2004) Immunosuppressive drug interactions with antiinfective agents. Am J Transplant 4 Suppl 10: 164-166.

21. Bennett WM, Henrich WL, Stoff JS (1996) The renal effects of nonsteroida anti-inflammatory drugs: summary and recommendations. Am J Kidney Dis 28: S56-62.

22. Bombardier C, Laine L, Reicin A, Shapiro D, Burgos-Vargas R, et al. (2000) Comparison of upper gastrointestinal toxicity of rofecoxib and naproxen in patients with rheumatoid arthritis. VIGOR Study Group. N Engl J Med 343: 1520-1528, 2 p following 1528.

23. Davies G, Kingswood C, Street M (1996) Pharmacokinetics of opioids in renal dysfunction. Clin Pharmacokinet 31: 410-422.

24. Bullo M, Tschumi S, Bucher BS, Bianchetti MG, Simonetti GD (2012) Pregnancy outcome following exposure to angiotensin-converting enzyme inhibitors or angiotensin receptor antagonists: a systematic review. Hypertension 60: 444-450.

25. Hoeltzenbein M, Elefant E, Vial T, Finkel-Pekarsky V, Stephens S, et al (2012) Teratogenicity of mycophenolate confirmed in a prospective study of the European Network of Teratology Information Services. Am J Med Genet A 158A: 588-596. 